\title{
THE
}

\section{The association between impulsivity and alcohol/drug use among prison inmates}

\author{
Michael H. Bernstein \\ University of Rhode Island \\ Savannah N. McSheffrey \\ University of Rhode Island \\ Jacob J. van den Berg \\ Jamie E. Vela \\ University of Rhode Island \\ L.A.R. Stein \\ University of Rhode Island, larstein@uri.edu \\ Follow this and additional works at: https://digitalcommons.uri.edu/psy_facpubs

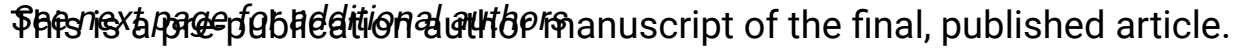 \\ Creative Commons License \\ (c) $(i) \Theta$
}

This work is licensed under a Creative Commons Attribution-Noncommercial-No Derivative Works 4.0 License.

\section{Citation/Publisher Attribution}

Bernstein, M. H., McSheffrey, S. N., van den Berg, J. J., Vela, J. E., Stein, L.A.R., Roberts, M. B., Martin, r. A., \& Clarke, J. G. (2015). The association between impulsivity and alcohol/drug use among prison inmates. Addictive Behaviors, 42, 140-143. doi: 10.1016/j.addbeh.2014.11.016

Available at: https://doi.org/10.1016/j.addbeh.2014.11.016

This Article is brought to you for free and open access by the Psychology at DigitalCommons@URI. It has been accepted for inclusion in Psychology Faculty Publications by an authorized administrator of DigitalCommons@URI. For more information, please contact digitalcommons-group@uri.edu. 


\section{Authors}

Michael H. Bernstein, Savannah N. McSheffrey, Jacob J. van den Berg, Jamie E. Vela, L.A.R. Stein, Mary B. Roberts, Rosemarie A. Martin, and Jennifer G. Clarke 


\section{The Association Between Impulsivity and Alcohol/Drug Use Among Prison Inmates}

Michael H. Bernstein ${ }^{a}$, Savannah N. McSheffrey ${ }^{a}$, Jacob J. van den Berg ${ }^{b, c}$, Jamie E. Vela ${ }^{a}$, LAR Stein ${ }^{\mathrm{a}, \mathrm{d}, \mathrm{e}}$, Mary B. Roberts ${ }^{\mathrm{f}, \mathrm{g}}$, Rosemarie A. Martin ${ }^{\mathrm{h}}$, and Jennifer G. Clarke ${ }^{\mathrm{f}, \mathrm{g}}$

aUniversity of Rhode Island, Department of Psychology 10 Chafee Rd. Kingston, RI 02811, USA

${ }^{b}$ Alpert Medical School of Brown University 222 Richmond St., Providence, RI 02903, USA

'Brown University School of Public Health, 121 South Main Street, Providence, RI 02912, USA

dBrown University, Center for Alcohol \& Addiction Studies 121 South Main Street, Providence RI 02906 USA

${ }^{e}$ Rhode Island Training School 600 Howard Ave, Cherrydale Court, Cranston, RI 022920, USA

fBrown University Center for Primary Care and Prevention Pawtucket, RI 02860, USA

9Memorial Hospital of Rhode Island Pawtucket, RI 02860, USA

hBrown University, Department of Behavioral \& Social Sciences Providence, RI 02912

\section{Abstract}

Background-Few studies have examined the relation between impulsivity and drug involvement with prison inmates, in spite of their heavy drug use. Among this small body of work, most studies look at clinically relevant drug dependence, rather than drug use specifically.

Method $-N=242$ adult inmates ( $34.8 \%$ female, $52 \%$ White) with an average age of 35.58 $(S D=9.19)$ completed a modified version of the 15-item Barratt Impulsivity Scale (BIS) and measures assessing lifetime alcohol, opiates, benzodiazepines, cocaine, cannabis, hallucinogens, and polysubstance use. Lifetime users also reported the frequency of use for the 30 days prior to incarceration.

Results-Impulsivity was higher among lifetime users (versus never users) of all substances other than cannabis. Thirty day drug use frequency was only related to impulsivity for opiates and alcohol.

(C) 2014 Elsevier Ltd. All rights reserved.

Correspondence regarding this article should be sent to the first-author at mbernstein11@ my.uri.edu; 401-874-5025; Cancer Prevention Research Center, 130 Flagg Rd, Kingston RI, 02881.

Publisher's Disclaimer: This is a PDF file of an unedited manuscript that has been accepted for publication. As a service to our customers we are providing this early version of the manuscript. The manuscript will undergo copyediting, typesetting, and review of the resulting proof before it is published in its final citable form. Please note that during the production process errors may be discovered which could affect the content, and all legal disclaimers that apply to the journal pertain.

Author Disclosures

No authors have any conflict of interests to report 
Discussion-This study extends prior work, by showing that a lifetime history of nonclinical substance use is positively associated with impulsivity among prison inmates. Implications for drug interventions are considered for this population, which is characterized by high rates of substance use and elevated impulsivity.

\section{Keywords}

impulsivity; alcohol; drugs; prison; inmates; substance use

\section{Introduction}

Prison inmates are especially vulnerable to substance use and misuse. Over half (56\%) of state prison inmates have used at least one illicit substance in the month before their offense (Mumola \& Karberg, 2006) whereas less than 25\% of the general adult population reports past month illicit drug use (Johnston et al., 2013). Moreover, 32\% of inmates were under the influence of drugs when committing their crime (Mumola \& Karberg, 2006).

Since 1980, the number of U.S. inmates has risen drastically (Harrison \& Beck, 2003), and there are currently more than 2.2 million adults held in federal prisons, state prisons, or local jails (Glaze \& Herberman, 2013). The late $20^{\text {th }}$ century increase is partly due to more punitive sentences for drug-related crimes and high rates of substance use disorders (SUD) (Belenko \& Peugh, 1998; Blumstien \& Beck, 1999), which is estimated at around 50\% among prison inmates (Mumola \& Karberg, 2006).

\subsection{Impulsivity and Substance Use}

The relation between personality and substance use disorders is well established (e.g., Caspi at al., 1997; Sher, Trull, Bartholow, \& Veith, 1999). Of note, impulsivity, a personality construct indicative of sensation seeking, perseverance, lack of premeditation, and urgency (Whiteside \& Lyman, 2001), is related to alcohol and drug abuse (Perry \& Carroll, 2008). Impulsivity is a risk factor for drug experimentation and people who use drugs are typically more impulsive than those who do not (de Wit, 2009). Similarly, impulsivity is positively associated with alcohol and illicit drug use frequency (Hanson, Luciana, \& Sullwood, 2008), while the related trait of novelty-seeking is prospectively associated with an increased likelihood of developing an SUD (Sher, Bartholow, \& Wood, 2000).

A small body of research has examined the relation between impulsivity and substance use/ dependence among an incarcerated population. In two studies, impulsivity was related to a global assessment of drug use severity among male (Ireland \& Higgins, 2013) and female (Mooney et al., 2008) adult inmates. Although these studies are informative, both used the Drug Abuse Screening Test, which only assesses general drug dependence, rather than asking about specific substances (i.e. "Have you ever felt bad or guilty about your drug abuse" versus "Have you ever felt bad or guilty about your alcohol abuse"). However, in a recent study, Hopley and Brunelle (2012) examined the relation between drug use and impulsivity with greater specificity by assessing alcohol, cannabis, opiod, stimulant, and hallucinogen dependence separately. For each of these substances, inmates with probable dependence scored higher on impulsivity than those without probable dependence. Among 
adolescents mandated to substance abuse treatment, those in the top 50 percentile of impulsivity, measured with the Millon Adolescent Clinical Inventory (MACI) Impulsivity Scale, reported more past 3-month alcohol and marijuana use relative to those who scored on the bottom half of impulsivity (Devieux et al., 2002). Although not statistically significant, cocaine was also more prevalent in the high impulsive group.

Impulsivity has been identified as a risk factor for substance use/abuse generally, but it has rarely been examined among incarcerated adults despite their high rates of substance use, and the need for tailored interventions to keep prisoners from relapsing upon their release. The few studies that have examined the impulsivity - substance use/abuse relation among this population often use general assessments of drug dependence (or probable dependence) among male- or female- only inmates (e.g. Hopley \& Brunelle, 2012; Ireland \& Higgins, 2013; Mooney et al., 2008). Only one of these studies (Devieux et al., 2002) has looked at substance use frequency (as opposed to dependence symptoms), but did so with a narrow range of substances (alcohol, marijuana and cocaine) among adolescents only. Although many prisoners do meet criteria for substance abuse or dependence, others have a history of drug involvement below those thresholds (Mumola \& Karberg, 2006). There is currently a gap in the literature addressing this broader population, which the current study sought to fill. Accordingly, the present study was designed to examine the relation between impulsivity and the use of several substances in a mixed-gender sample of adult inmates. We hypothesized that impulsivity would be higher among participants with a lifetime history of drug use. We also expected a positive relation between impulsivity and the frequency of substance use.

\section{Method}

\subsection{Participants and Procedures}

This study is a secondary data analysis using baseline data from a randomized controlled trial (RCT) that has been reported elsewhere (Clarke et al., 2011; Clarke et al., 2013). In brief, the RCT examined the effectiveness of a six-session smoking cessation intervention using cognitive-behavioral therapy enhanced with motivational interviewing in comparison to a general wellness video control condition. The study was conducted in a large tobaccofree state correctional facility located in the northeastern U.S. All study procedures were approved by a variety of relevant IRBs.

Both men and women inmates who were interested in participating were screened for eligibility and met inclusion criteria if they were: 18 years of age or older, smoked at least ten cigarettes per day prior to incarceration, able to speak English, and scheduled to be released within eight weeks of study enrollment. In total, $84 \%$ of participants who were screened met eligibility criteria and participated in the study at baseline. After providing informed consent, participants completed a baseline assessment via Audio ComputerAssisted Self-Interview. Although 247 participants completed this study, the sample used here is comprised of $N=242$ inmates due to missing data for five participants. See Table 1 for a description of the sample. 


\subsection{Measures}

The independent variable of interest for all analyses was impulsivity, which was assessed with a modified version of the BIS15 (Spinella, 2007) from the 30 item Barratt Impulsiviness Scale (BIS-11; Patton, Stanford, \& Barratt, 1995). It is a valid measure of impulsivity, constructed by taking items with the highest loadings from the BIS-11 (Spinella). Due to experimental error, however, one item "I am restless at lectures or talk" was not administered to participants, so the measure used here is comprised of the remaining 14 items. All items were on a 4-point Likert scale, with potential scores ranging from 1 to 4 . We observed a co-efficient alpha of .779.

Substance use was assessed with a modified version of the Addiction Severity Index (ASI; McLellan, Luborsky, O'Brien, \& Woody, 1980). Participants were asked to indicate if they had ever used a particular substance (yes/no), and if so, how many days they used that substance in the 30 days prior to incarceration. Specific substances included: alcohol, heroin, methadone, other opiates/pain killers, barbiturates, sedatives or benzodiazepines, cocaine, amphetamines, cannabis, hallucinogens, inhalants, and more than one substance per day (including alcohol). For alcohol, participants were also asked "How many drinks do you have on a day when you are drinking?" For other opiates/pain killers, barbiturates, and sedatives or benzodiazepines, participants were only asked to report their use that was "nonprescribed, or taken not as prescribed."

An alcohol quantity/frequency variable was created by multiplying the number of days alcohol was used in the past 30 by the average number of drinks per drinking day. We also created a composite opiate variable to include: heroin, methadone, and pain killers or other opiates. As such, lifetime opiate use entails anyone who used at least one of those substances, while opiate frequency entails the 30 day sum of heroin, methadone, and pain killers or other opiates.

Prior to conducting analyses, frequencies were run to determine the number of participants who had endorsed ever using each substance. Due to potential floor effects, we excluded substances from all analyses when less than $20 \%$ of participants reported lifetime use, which was the case for barbiturates (10.5\%), amphetamines (16.0\%), and inhalants (11.3\%). We also excluded alcohol from analyses comparing lifetime users to never users due to a ceiling effect ( $94 \%$ reported lifetime use).

\subsection{Analytic Plan}

To determine the relation between impulsivity and drug use, we ran a series of regression models. Logistic Regression (LR) was used to compare impulsivity between ever- and never- substance users. We examined the relation between substance use frequency (or quantity/frequency in the case of alcohol) and impulsivity among participants who reported ever having used the substance. For normally distributed variables, we used ordinary least squared regression (OLS). Alcohol quantity/frequency and hallucinogen frequency, however, were highly zero-inflated, and thus unsuitable for OLS (skewness $>|2|$, kurtosis $>\mid$ $4 \mid$ ). As such, we used Poisson regression to determine the relation between these variables and impulsivity. 
For logistic and OLS regression, all analyses were conducted in two steps with gender and age entered as covariates on step 1 , and impulsivity entered on step 2 . These covariates were selected because they were related to drug use (outcome), but unrelated to impulsivity (independent variable of interest). In LR analyses, a binary outcome of ever having used a drug was entered as the dependent variable (DV). In OLS analyses, the outcome was frequency of use during the 30 days prior to incarceration. Poisson regression analyses were conducted by simultaneously including age, gender, and impulsivity into one model.

\section{Results}

Across the total sample, the mean impulsivity score was $2.50(S D=2.46)$. Impulsivity was higher among ever-users (versus never-users) for all drugs other than cannabis. However, for most of these substances, frequency of use during the 30 days prior to incarceration was unrelated to impulsivity. Notable exceptions include opiate frequency and alcohol quantity/ frequency. See Table 2 for a full description of these results.

\section{Discussion}

The purpose of this study was to examine the relation between impulsivity and alcohol/drug use among prison inmates. We found that impulsivity was related to the likelihood of having used all substances other than marijuana. With the exception of alcohol and opiates, however, it was unrelated to the frequency of substance use. This study expands upon previous work showing the relation between substance use and drug dependence in an incarcerated population (Hopley \& Brunelle, 2012; Ireland \& Higgins, 2013; Mooney et al., 2008) by looking at the relation between impulsivity and non-clinical use of a variety of substances. Although Devieux and colleagues (2002) examined this association among incarcerated adolescent, results were restricted to alcohol, marijuana, and cocaine. The current study, by contrast, included a variety of illicit drugs among adult inmates. Of note, Devieux et al found that marijuana and impulsivity were related, while no association was observed here.

\subsection{Limitations and Future Directions}

Due to the cross-sectional design, we are unable to examine directionality. Although this study conceptualized impulsivity as a risk factor for drug use, it is possible that drug use caused impulsivity, as has been found in other research (see de Wit, 2009 for a review). However, studies looking at drug use as an antecedent of impulsivity typically analyze the acute effect of drug administration on immediate impulsive behavior. Since participants in this study were imprisoned, they were presumably not experiencing acute drug effects at the time of answering survey items assessing impulsivity. As such, it seems unlikely that the directionality would go in the opposite direction as hypothesized.

While the timing of measures minimizes concern about the directionality of effect, it raises concern about the accuracy of reporting. Participants were asked to reflect upon drug use for the 30-day period prior to incarceration, which was an average of 1.2 years ago. This time lag could result in bias reporting due to memory lapses. Finally, these data were only 
collected in one New England correctional facility, so the extent to which the results generalize to a broader inmate population is unclear.

Relative to the general population, inmates are at an elevated risk of substance use (Mumola $\&$ Karberg, 2006) and are more impulsive (Patton et al., 1995). Since our study, as well as other work (Hopley \& Burnelle, 2012; Ireland \& Higgins, 2013; Mooney et al., 2008), suggests impulsivity and drug involvement are positively related in this population, future research could consider tailoring prison interventions to reduce both impulsivity and substance use. Doing so might improve post-release outcomes, since most fatalities among inmates soon after re-entry are drug related (Merrall et al., 2010), and inmates who report substance use after release face greater unemployment (Visher, Debus, \& Yahner, 2008).

\section{Acknowledgements}

This project was funded by R01DA024093 from the National Institutes of Health/National Institute on Drug Abuse awarded to J.G. Clarke

Michael Bernstein wrote the results section and ran all analyses. He also made substantial contributions to the introduction and discussion sections. Savannah McSheffrey helped draft the introduction. Jacob van den Berg was the primary author for the method section. Jamie Vela helped draft the discussion. Jacob van den Berg, LAR Stein, Mary Roberts, Rosemarie Martin, and Jennifer Clarke read through all parts of the manuscript and provided significant guidance for later drafts of the paper. Additionally, Mary Roberts, LAR Stein, Jennifer Clarke, and Rosemarie Martin helped with data analysis and interpretation. LAR Stein, Mary Roberts, Rosemarie Martin, and Jennifer Clarke (Principle Investigator) were also involved in the NIDA grant which funded data collection. All authors have approved the final manuscript draft.

\section{References}

Belenko S, Peugh J. Fighting crime by treating substance abuse. Issues in Science and Technology. 1998; 15:53-60.

Blumstein, A.; Beck, AJ. Population growth in U.S. prisons, 1980-1996. In: Tonry, M.; Petersilia, J., editors. Prisons. Chicago, IL: University of Chicago Press, Chicago; 1999. p. 17-61.

Caspi A, Begg D, Dickson N, Harrington H, Langley J, Moffitt TE, Silva PA. Personality differences predict health-risk behaviors in young adulthood: Evidence from a longitudinal study. Journal of Abnormal Psychology. 1997; 73:1052-1063.

Clarke JG, Martin RA, Stein LAR, Lopes CE, Mello J, Friedmann P, Bock B. Working Inside for Smoking Elimination (Project W.I.S.E.) study design and rationale to prevent return to smoking after release from a smoke free prison. BMC Public Health. 2011; 11:767-772. [PubMed: 21974746]

Clarke JG, Stein LAR, Martin RA, Martin SA, Parker D, Lopes CE, Bock B. Forced Abstinence: Not Enough for Smoking Cessation. JAMA Internal Medicine. 2013; 173:789-794. [PubMed: 23567902]

de Wit H. Impulsivity as a determinant and consequence of drug use: a review of underlying processes. Addiction biology. 2009; 14:22-31. [PubMed: 18855805]

Dévieux J, Malow R, Stein JA, Jennings TE, Lucenko BA, Averhart C, Kalichman S. Impulsivity and HIV risk among adjudicated alcohol-and other drug-abusing adolescent offenders. AIDS education and prevention: Official publication of the International Society for AIDS Education. 2002; 14S:2435. [PubMed: 12413190]

Glaze, LE.; Heberman, EJ. Correctional populations in the United States, 2012. Publication No. NCJ 243936. Washington, D.C.: U.S. Department of Justice, Bureau of Justice Statistics; 2013.

Hanson KL, Luciana M, Sullwold K. Reward-related decision-making deficits and elevated impulsivity among MDMA and other drug uses. Drug and alcohol dependence. 2008; 96:99-110. [PubMed: 18384979] 
Harrison, PM.; Beck, AJ. Prisoners in 2002. Publication. No. NCJ 200248. Washington, DC: U.S. Department of Justice, Bureau of Justice Statistics; 2003.

Hopley AAB, Brunelle C. Personality mediators of psychopathy and substance dependence in male offenders. Addictive Behaviors. 2012; 37:947-955. [PubMed: 22543034]

Ireland JL, Higgins P. Behavioural stimulation and sensation-seeking among prisoners: Applications to substance dependency. International Journal of Law and Psychiatry. 2013; 36:229-234. [PubMed: 23623718]

Johnston, LD.; O'Malley, PM.; Bachman, JG.; Schulenberg, JE. Monitoring the Future national survey results on drug use, 1975-2012: Volume 2, College students and adults ages 19-50. Ann Arbor: Institute for Social Research, The University of Michigan; 2013.

Merrall ELC, Kariminia A, Binswanger IA, Hobbs MS, Farrell M, Marsden J, Bird SM. Meta-analysis of drug-related deaths soon after release from prison. Addiction. 2010; 105:1545-1554. [PubMed: 20579009]

Mooney JL, Minor KI, Wells JB, Leukefeld C, Oser CB, Tindall MS. The relationship of stress, impulsivity, and beliefs to drug use severity in a sample of women prison inmates. International journal of offender therapy and comparative criminology. 2008; 52:686-697. [PubMed: 18040061]

McLellan AT, Luborsky L, O'Brien CP, Woody GE. An improved diagnostic instrument for substance abuse patients: The Addiction Severity Index. Journal of Nervous \& Mental Diseases. 1980; 168:26-33.

Mumola, CJ.; Karberg, JC. Drug use and dependence: State and federal prisoners. Vol. 2004. Washington, DC: US Department of Justice; 2006.

Patton JH, Stanford MS, Barratt ES. Factor structure of the Barratt Impulsiveness Scale. Journal of Clinical Psychology. 1995; 51:768-774. [PubMed: 8778124]

Perry JL, Carroll ME. The role of impulsive behavior in drug abuse. Psychopharmacology (Berl). 2008; 200:1-26. [PubMed: 18600315]

Sher KJ, Bartholow BD, Wood MD. Personality and Substance Use Disorders: A prospective study. Journal of Consulting and Clinical Psychology. 2000; 68:818-829. [PubMed: 11068968]

Sher, KJ.; Trull, TJ.; Bartholow, B.; Vieth, A. Personality and alcoholism: Issues, methods, and etiological processes. In: Blane, H.; Leonard, K., editors. Psychological theories of drinking and alcoholism. 2nd edition. New York: Plenum; 1999. p. 55-105.

Spinella M. Normative data and a short form of the Barratt Impulsiveness Scale. International Journal of Neuroscience. 2007; 117:359-368. [PubMed: 17365120]

Visher, C.; Debus, S.; Yahner, J. Employment after release: A longitudinal study of releases in three states. Washington, DC: Urban Institute; 2008.

Whiteside SP, Lynam DR. The Five Factor Model and impulsivity: Using a structural model of personality to understand impulsivity. Personality and Individual Differences. 2001; 30:669-689. 


\section{Highlights}

- Examine association between impulsivity and substance use

- Use large, mixed-gender inmate sample

- $\quad$ Analyze non-clinical drug use 


\section{Table 1}

\section{Study Characteristics}

\begin{tabular}{|c|c|}
\hline Demographic & Percent of Sample \\
\hline \multicolumn{2}{|l|}{ Age $(M=35.58, S D=9.19)$} \\
\hline $19-28$ & 26.9 \\
\hline $29-38$ & 35.1 \\
\hline $39-48$ & 28.3 \\
\hline $49+$ & 9.1 \\
\hline \multicolumn{2}{|l|}{ Gender } \\
\hline Male & 65.2 \\
\hline Female & 34.8 \\
\hline \multicolumn{2}{|l|}{ Race/Ethnicity } \\
\hline Non-Hispanic White & 52.0 \\
\hline Hispanic White & 8.2 \\
\hline Non-Hispanic Black & 17.6 \\
\hline Hispanic Black & 3.7 \\
\hline Hispanic Other & 8.2 \\
\hline Native American/Alaskan Native & 4.9 \\
\hline Asian or Pacific Islander & 0.8 \\
\hline Bi-racial or multi-racial & 1.6 \\
\hline Other & 2.9 \\
\hline \multicolumn{2}{|l|}{ Highest level of Education Completed } \\
\hline Did not complete High School & 64.6 \\
\hline Completed $12^{\text {th }}$ grade & 20.2 \\
\hline Completed $\geq 1$ year of college & 8.2 \\
\hline \multicolumn{2}{|c|}{ Time Incarcerated ${ }^{a}(M=1.20, S D=1.58$ years $)$} \\
\hline Less than 6 months & 42.7 \\
\hline $6-12$ months & 26.2 \\
\hline 13-24 months & 14.7 \\
\hline $25+$ months & 16.4 \\
\hline
\end{tabular}

${ }^{a}$ Participants were asked: "How long has it been since you smoked daily?" We used these responses as a proxy for time incarcerated, since all participants were daily smokers prior to incarceration, but unable to smoke in the Rhode Island correctional facility. 
로을

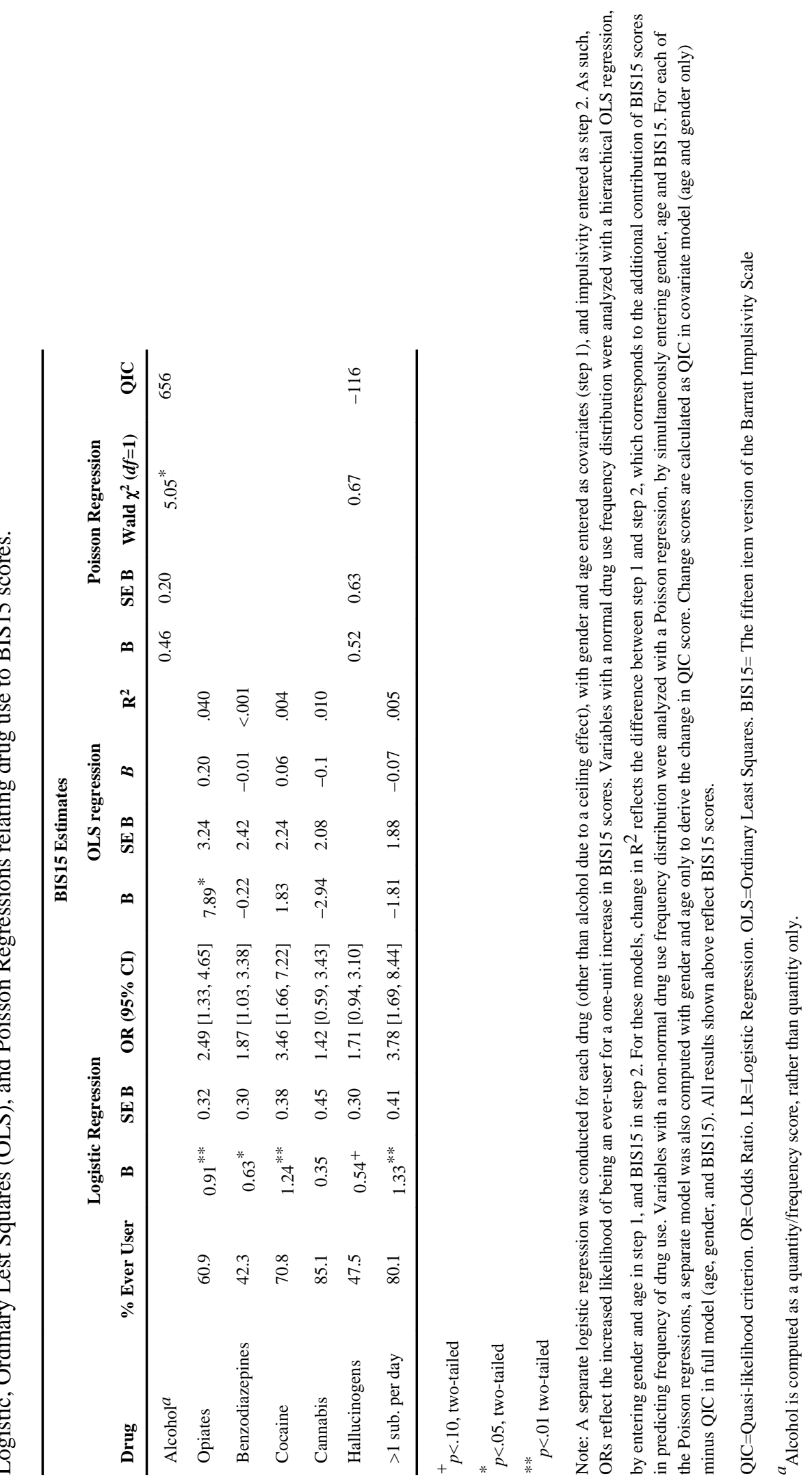

Addict Behav. Author manuscript; available in PMC 2016 March 01. 